by the furane ring, fural-pyruvic acid (IX) being even more active than benzal-pyruvic acid (VIII) :

$\mathrm{C}_{6} \mathrm{H}_{5}-\mathrm{CH}=\mathrm{CH}-\mathrm{CO}-\mathrm{COOH}$

VIII

$\mathrm{C}_{8} \mathrm{H}_{3} \mathrm{O}-\mathrm{CH}=\mathrm{CH}-\mathrm{CO}-\mathrm{COOH}$ IX

Recent experiments suggest the possibility of getting œstrogenetic activity in ring-free compounds by arranging the carbon atoms 13, 14, 8, 9 of ostrin in a suitable way. Work is in progress to see whether these results can be confirmed by the capon-plumage test.

The application of the views developed above for the preparation of cancer producing substances can easily be seen. Investigations in this direction have boen started.

Sir William Dunn Institute of Biochemistry, University, Cambridge. Feb. 25.

${ }^{1}$ o. Blum, E. Bergmann, Naturwiss., 21, 578; 1933.

J. W. Cook, E. C. Dodds, C. L. Hewett, NATURE, 131, 56; 1933. 3 E. Friedmann, Helv. Chim. Acta, 14, 783; 1931.

E. Friedmann and H. Mai, Helv. Chim. Acta, 14, 1213; 1931.

5 M. Reimer, J. Amer. Chem. Soc. 48, 2454; 1926.

\section{A Gyroscopic Top which will Walk Down Steps}

IN his book on "Gyrostatics and Rotational Motion", the late Prof. Andrew Gray explained how a top can be made to move along two parallel horizontal wires when they are rocked so as to change the point of support from one wire to the other. A fow years ago, I discovered that a spinning top will automatically walk down two parallel wires arranged as an inclined plane.

While working with high speed motors, it occurred to me that a rapidly spinning top would have a very slow precession and could be made to walk down two wires bent so as to form a succession of steps. The top and steps are shown in Fig. 1.

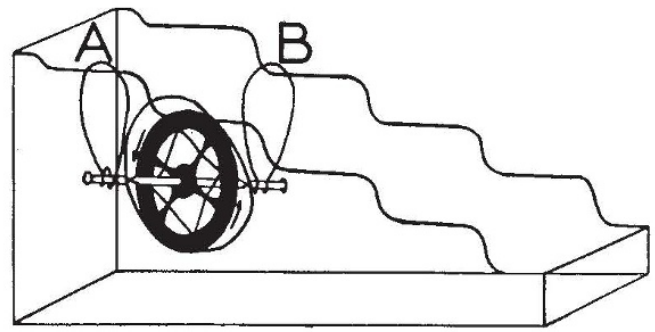

FIG. 1.

My assistant, Mr. Fullmer, who built the top, found that the length of the steps and the height of the risers must be very accurately proportioned to the type of top used. The steps should not form a sharp corner with the risers, but must be curved at each junction.

The top is spun at four to five thousand revolutions per minute and held with one hook in the middle of the highest step while the hook on the opposite side is pressed against the second highest riser (see points $A$ and $B$ in Fig. 1). The top, when released, will walk down the steps.

Department of Physics,

West Virginia University.

\section{Infra-Red Photography of Coal}

IN a letter in NATURE of February 2 (p. 265) Prof. J. Walton has remarked that infra-red photography of thin sections of coal should give interesting results. We would like to direct attention to some results of work on this subject.

We should mention first that there are already some references to this topic in the literature of coal petrography - for example, Klingner ${ }^{1}$, Boddy $^{2}$, and Wandless and Macrae $^{3}$. The last-mentioned paper includes a few illustrations of infra-red photographs of coal sections made by one of the present writers.

Besides these examples, however, several hundred other photomicrographs have been taken in this laboratory, and the infra-red plate has proved more generally useful than the panchromatic. Our experience of the two types of plates enables us to make the following generalisations concerning their use in this class of work.

(1) The principal advantage of the infra-red plate will be better understood if we first consider briefly the special photographic problems presented by coal sections. These sections consist of heterogeneous mixtures of substances of the following colours : white (empty spaces), brilliant yellow (spores and cuticles), and a continuous series of shades from pale red through deep red to black (vitrain, fusain, etc.). Obviously it is extremely difficult to make realistic pictures of such objects in black and white, no matter what photographic plate is used. In order to obtain detail in any one of these colours, detail in others must necessarily be sacrificed.

Panchromatic plates, even when the developing and printing process is adjusted to give a 'soft' effect, generally give prints which suggest that the colour transition between pale red and black is less gradual than is actually the case. In infra-red photographs, however, this defect is considerably reduced; hence they generally produce much more realistic pictures.

(2) There are special cases in which the panchromatic is still to be preferred to the infra-red plate; for example, photographs of cell structure in vitrain. In such cases, there may be no yellows and whites to be depicted, the entire field consisting of reds ; so, contrary to the usual rule, 'contrasty' prints may be required.

(3) Infra-red plates show another advantage over panchromatics for this work. The field appears to be flattened.

(4) Our laboratory methods for infra-red photography involve the use of the Ilford infra-red plate in conjunction with the deep red filter specified by the plate-makers, and a light source sufficiently intense to enable the image to be focused by eye. Using a weaker light and focusing by computation has not proved a success.

\section{J. J. WALKER.}

L. Slater.

Coal Survey Laboratory,

Portobello Street, Sheffield.

March 22.

${ }^{1}$ Montanistische Rundschau, 26, 1; 1934.

${ }^{2}$ Eleventh Annual Report, Safety in Mines Researth Board, p. 16; 1932 .

${ }^{3}$ Fuel in Science and I'ractice, 13, 4; 1934. 